\title{
Astheno-association: hard tick species new association type identified during the summer season 2019 on cattle in Jijel area, Algeria
}

\author{
Derradj Lotfi ( $\square$ lotfi.derradje@umc.edu.dz ) \\ University of Mentouri
}

\author{
Research Article \\ Keywords: ticks, association, correlation, similarities, positively, Jijel, Algeria \\ Posted Date: April 2nd, 2021 \\ DOI: https://doi.org/10.21203/rs.3.rs-382878/v1 \\ License: (c) (1) This work is licensed under a Creative Commons Attribution 4.0 International License. Read Full License
}




\section{Abstract}

To this date, ticks remain the major problem in the livestock sector because of their role as vectors for serious agents of disease propagation. Given the scarcity of studies on ticks in Algeria, associations of species were mentioned in only one document and were not well detailed in another. This paper is a synoptic review of seven tick species associations related to host biotic factors in Algeria. The aim is to better understand the behaviour and biology of ticks to propose a new control method based on the association index. A total of 53 infested cattle were detected and 1,214 ticks were manually collected and identified based on their morphology during the summer of 2019 (June to August). Seven tick species were identified: viz. Rhipicephalus (Boophilus) annulatus, Rhipicephalus bursa, Rhipicephalus sanguineus, Hyalomma marginatum, Hyalomma lusitanicum, Hyalomma scupense, and Hyalomma anatolicum. The Principal Component Analysis (PCA) was used as an analytical tool to visualize similarities and correlations between cattle and females, males of tick species, according to three biotic factors (age, sex and breed of cattle). The results show that there is a relationship between the number of associated species and biotic factors (age of livestock). In addition, the degree of association is influenced by the host and other tick species and a new type of "astheno-association" is emerging that limits the number of associated species to two or three.

\section{Introduction}

Ticks are veterinary and medically important arthropods because of their vectorial capacity. They are known as vectors for human and animal pathogens (protozoa, bacteria, viruses) and transmit a wider variety of infectious organisms (Nicholson et al., 2009). Host preferences and tick distribution are both important in understanding the ecology and epidemiology of tick-borne diseases (Mihalca et al., 2012). Given the paucity of tick studies in Algeria (YousfiMonod and Aeschlimann, 1986; Boulkaboul, 2003; Elfegoun et al., 2007; 2013; 2018; 2019), only two studies are available in Algeria on tick species association. In addition, the only comprehensive study on tick associations in Algeria was published more than 34 years ago.

The first study was carried out in 1986 by Yousfi-Monod and Aeschlimann. The authors found that the association degree vary between two to four species in the twelve species identified in 2086 cattle during two years (1981 to 1983). Furthermore, they identified two types of associations under abiotic factors, both types being related to the breeding methods and the geographical origin of the cattle. They reported that competition-exclusion was not observed. The same authors recommended statistical analysis of species associations, but no studies have been conducted so far.

The second study, carried out by Boulkaboul (2003), only underlined that "several species can parasitize the same animal. The minimum association of two species was observed in January and the maximum association (five species) in June. This of course conditions the parasitic load of an animal at a given time". In addition, most of the data on species associations are rather rare and old and are only available in Japan (Takashi 2007), thus not easily accessible to researchers for comparative studies. In addition, similar synoptic papers have not been published recently.

This study aims to address the following questions: (1) Which biotic factor is primarily chosen by ticks? (2) Is the degree of association influenced by the host or by other tick species? (3) Where are associations of less than four species most frequent? (4) Is there or is there not a new type of association based on biotic factors? PCR analysis was used to test for similarities and correlation between species with dissimilar host biotic factors.

\section{Materials And Methods Study area}

This study was carried out in the province of Jijel, in northeastern Algeria (Fig. 1), in June, July and August 2019. Jijel is located between $36^{\circ} 48^{\prime} \mathrm{N}$ and $5^{\circ} 46^{\prime} \mathrm{E}$, covers $2,577 \mathrm{~km}^{2}$. The climate is warm temperate with a typical hot and relatively dry season between June and August and a wet season from November to April dominate the region. Annual rainfall varies and the monthly temperature is between 800 and $900 \mathrm{~mm} /$ year, or 11.3 and $26^{\circ} \mathrm{C}$ respectively. The hottest and driest months in Jijel are August and July (Source: climate-data.org).

\section{Sampling}

The number of cattle herds in Jijel is estimated at 87,942 head (Hamiroune et al., 2019). There are 53 cattle including 7 males (13.20\%) and 46 females (86.80\%) belonging to three breeds: Brown Atlas ( $n=19 ; 35.85 \%)$, Breton Blackfoot $(n=30 ; 56.60 \%)$ and Plain Redfoot $(n=4 ; 7.55 \%)$. The different age groups selected for this study are as follows: less than one year old $(n=3 ; 5.66 \%)$, two years old $(n=5 ; 9.43 \%)$, three years old $(n=7 ; 13.21 \%)$, four years old ( $n=3$; $5.66 \%)$, five years old $(n=5 ; 9.43 \%)$, six years $(n=8 ; 15.09 \%)$, seven years $(n=7 ; 13.21 \%)$, eight years $(n=10 ; 18.77 \%)$, nine years $(n=3.77 \%)$ and less than eleven years $(n=3 ; 5.66)$.

An extensive system is used for cattle breeding in the study area. Cattle are kept on pasture 24 hours a day and cows are only brought in for calving. Farmers apply anti-tick control acaricides randomly and irregularly. For this study, ticks were manually removed from the skin surface of infested cattle; 1,214 ticks were collected and stored in vials containing $70 \%$ ethanol. Data on the age, breed and sex of the cattle were meticulously recorded, and the ticks were then identified in the laboratory of biosystematics and ecology of arthropods under a stereomicroscope according to the key of Walker et al. (2003).

\section{Statistical analysis}

All data was exported to an Excel ${ }^{\circledR}$ spreadsheet for Windows ${ }^{\circledR}$. Principal Component Analysis (PCA) was performed using PAST ${ }^{\circledR}$ for Window ${ }^{\circledR}$. It was used to visualize relationships between variables (female and male tick species) and similarities between observations (age, sex, and breed of cattle), understand the relationship between variables when analysing many variables, discover patterns and reduce a large amount of data to a subset of interesting 
relationships, and describe the strength of a relationship between two variables. For the PCA, 14 variables (seven species; females, males) were considered, to assess correlations between tick species and biotic factors (cattle age, breed, and sex), while comparisons of infestation rate (prevalence and intensity) and association degree were made using the ANOVA test. All statistical tests performed were considered at a 5\% cut-off value (Schwartz, 1993).

\section{Results}

\section{Principal Component Analysis}

\section{Species associations}

A total number of 1,214 ticks were collected between June and August 2019 from cattle in the province of Jijel in northeastern Algeria. These ticks were identified based on their morphology; they belong to two genera, namely Rhipicephalus spp. and Hyalomma spp. and seven species, vis. Rh. (Boophilus) annulatus (74.62\%), Rh. bursa (10.46\%), Rh. sanguineus (0.32\%), Hy. anatolicum (1.56\%), Hy. lusitanicum (4.11\%), Hy. marginatum (5.51 \%) and Hy. scupense (3.37\%) (Table 1). Table 1 shows that the number of associated tick species in the same cattle changes from one to six, as follows: one species $(28.3 \%)$, two species (33.96\%), three species (24.53\%), four species $(5.66 \%)$, five species $(5.66 \%)$, six species $(1.88 \%)$ and seven species $(0 \%)$.

Cattle were scored on 53 factors. The scores of each cattle were combined into 3 biotic factors, using the seven species (females and males) as factors, then the scores of each factor were combined into an overall score and ranking for each cattle to create the scatter plot and correlation matrix. Intensity varied from 1 tick on female Breton Black Pied cattle under 5 years of age to 124 ticks on female Breton Black Pied cattle under 6 years of age with an average of 22 ticks/cattle (Table 1 and table 3). The most or least infested cattle (intensity $>40$ ticks) belong to Breton Black Pied cattle (8/53) and two Red Pied Lowland $(2 / 53)$. The least infested cattle is the Breton Black Pied (intensity $=1$ tick).

Figure 2 indicates the correlation matrix. It shows the correlation coefficient for each pair of tick species (females and males). From the scatter plot matrix of the correlation matrix, some relationships are evident, females and males of the tick species are negatively correlated, except for those of $H y$. marginatum and Rh.sanguineus.

The colour map (Figures 2) shows the structure of the components; absolute values close to zero indicate that a variable contributes little to the component, while larger absolute values indicate variables that contribute more to the components. The sign of the coefficients is not relevant.

\section{Similarities between cattle}

There is a significant relationship between the number of ticks of each species and the number of species associations $(p=7.78 \mathrm{E}-20)$. There is no statistically significant difference in the prevalence and intensity of infestation according to the degree of species association $(p>0.05)($ Table 5$)$.

Figures 2 show the two-dimensional approximation of the initial multidimensional space, which represents $70 \%$ of the initial variation in the data; each point in the plot represents a cattle and each axis represents a tick species, the distance between cattle represents the similarity between them; close points are cattle with similar profiles and distant points have dissimilar profiles. Any point in the plot can be projected orthogonally on the axes to show the approximate value of this variable.

\section{Discussion}

This study was carried out in June, July and August 2019 in the region of Jijel (humid climate) to consider the seasonal activity of the main vector tick species in north-eastern Algeria. 1,139 ticks were collected from 53 examined cattle. Seven species of ixodid ticks were collected from cattle, namely Rhipicephalus (Boophilus) annulatus, Rhipicephalus bursa, Rhipicephalus sanguineus, Hyalomma marginatum, Hyalomma scupense, Hyalomma lusitanicum, and Hyalomma anatolicum.

In the Jijel region of Algeria, male and female hard tick species are associated, and these associations vary widely depending on biotic factors, including the sex, breed and age of the cattle.

This study aims to address the following questions: (1) Which biotic factor is primarily chosen by ticks? : The major factor that affect the infestation rate is primordialy cattle sex. (2) Is the degree of association influenced by the host or by other tick species?: the degree of associations affect greatly the infestation rate, since these rate decreased when association degree increased (3) Where are associations of less than four species most frequent?: it is frequent in cattle age cattle age between five and seven years categories (4) Is there or is there not a new type of association based on biotic factors? Yes there is a new type of association was observed during the study and we chose to refer to it as astheno-association (from the Greek asthen (ës) "frail, weak, sickly"). This new type is clearly defined as "an exposure of 2 or 3 species depending on the biotic factors of the host, without exclusion or competition". Yousfi-Monod and Aeschlimann (1986) described two types of associations, the mode of reproduction and the geographical origin of the livestock. The same authors observed associations of two to four species, which differs from our results.

In this study, negative correlations were found between females and males of some species. The latter finding is evident since Hyalomma males are more mobile than females and stay longer on livestock. This result was also observed in dogs infested with the brown tick $R$. sanguineus (Little et al., 2007).

Micrometeorological and microhabitat factors on livestock are fundamental factors in tick survival and foraging behaviour (Daniel and Dusbabek, 1994). 
These factors are dispersed for ticks, and the age of the livestock largely affects the number of females and males. The same observations were made with regard to sex and breed.

Arthur (1962) reported that the degree of tick aggregation is highest in larvae but lowest in adults. A similar finding was made, with the number of infested cattle decreasing when the species associations changed to six species. In addition, spatial niche overlap was greater than temporal niche overlap in some tick species and there were interactions between tick species when at least two tick species occurred in the same season (Tsunoda, 2007). Host biotic factors determine the number of species due to coexistence, as has been observed with Rhipicephalus (Boophilus) annulatus and Rhipicephalus bursa. In addition, it can be advantageous to cluster in an optimal locality, as this can increase the chances of success (Tsunoda, 2007). The larger group offers a greater advantage to ticks even if the group includes other species (Tsunoda, 2007), which may explain why the association of more than three species is observed during the study period.

\section{Conclusion}

This paper aimed to investigate the behaviour and biology of ticks on cattle in Jijel area, in northeastern Algeria, to propose a new control method based on the association index. A total of 53 infested cattle were detected and 1,136 ticks were manually collected and identified on the basis of their morphology during the summer of 2019 (June, July and August). Seven species of ticks were identified: Rhipicephalus (Boophilus) annulatus, Rhipicephalus bursa, Rhipicephalus sanguineus, Hyalomma marginatum, Hyalomma lusitanicum, Hyalomma scupense and Hyalomma anatolicum. Principal Component Analysis (PCA) was used as an analytical tool to visualize the similarities and correlations between cattle and female, male ticks species, according to three biotic factors (age, sex and breed of cattle). Based on the results, we can conclude that there is a relationship between the number of associated species and biotic factors. The association degree is influenced by the host and other tick species, and the appearance of a new type of "astheno-association" is limited to two or three associated species.

\section{Declarations}

\section{Acknowledgements}

The authors are very grateful to the herdsmen who allowed them to take ticks from their cattle.

\section{Disclosure statement}

The authors reported no potential conflict of interest.

\section{Funding}

The current research received a grant from Arthropods Biosystematics and Ecology laboratory, Frères Mentouri - Constantine 1 University, Constantine, Algeria.

\section{References}

Arthur D. R. 1962. Ticks and disease. Pergamon Press, Oxford, U.K.,445 p.

Boulkaboul A. 2003. Parasitisme des tiques (Ixodidae) des bovins à Tiaret, Algérie. Revue d'élevage et de médecine vétérinaire des pays tropicaux. [Tick parasitism (Ixodidae) of cattle in Tiaret, Algeria.] 56(3-4) :157-162. French.

Boutaleb K. 1982. Les connaissances actuelles sur les tiques du bétail en Algérie. [dissertation]. Constantine: University of Constantine. [Current knowledge on livestock ticks in Algeria]. French.

Daniel M. and F. Dusba' Bek. 1994. Micrometeorological and microhabitat factors affecting maintenance and dissemination of tickborne diseases in the environment. In Ecological dynamics of tickborne zoonoses, D. E. Sonenshine and T. N. Mather (eds.). Oxford

University Press, Oxford, U.K., p. 91-138.

Elfegoun, MC Benakhla, A Bentounsi, B Bouattour, A Piarroux, R. 2007. Identification et cinétique saisonnière des tiques parasites des bovins dans la région de Taher (Jijel) Algérie. Annales de médecine vétérinaire. [Identification and seasonal kinetics of bovine parasite ticks in the Taher region (Jijel) Algeria] 151 : 209 214. French.

Elfegoun MB, Gharbi M, Djebir S, Kohil K. 2014. Dynamique d'activité saisonnière des tiques ixodidés parasites des bovins dans deux étages bioclimatiques du nord-est algérien. [Seasonal activity dynamics of parasitic ixodid ticks of cattle in two bioclimatic floors of northeastern Algeria] Revue d'élevage et de médecine vétérinaire des pays tropicaux. 66(4):117-122.

Elfegoun MCB, Kohil K, Gharbi M, Afoutni L, Benachour ML. 2019. Cinétique d'infestation par les tiques des bovins de la région subhumide de Constantine en Algérie. [Tick infestation kinetics of cattle in the subhumid region of Constantine, Algeria] Revue d'élevage et de médecine vétérinaire des pays tropicaux. 72(1) :41-45. French. 
Elfegoun MCB, Gharbi M, Merzekani Z, Kohil K. 2018. Piroplasmoses bovines dans les provinces de Skikda et d'Oum El Bouaghi (nord-est de l'Algérie) : étude épidémiologique et estimation des pertes de production laitière. Revue d'élevage et de médecine vétérinaire des pays tropicaux. [. Bovine Piroplasmosis in the provinces of Skikda and Oum El Bouaghi (northeastern Algeria): epidemiological study and estimate of losses in milk production.] 70(3):105-110. French.

Gharbi M, Hayouni ME, Sassi L, Dridi W, Darghouth MA. 2013. Hyalomma scupense (Acari, Ixodidae) in northeast Tunisia: seasonal population dynamics of nymphs and adults on field cattle. Parasite. 20.

Gharbi M, Darghouth MA. 2014. A review of Hyalomma scupense (Acari, Ixodidae) in the Maghreb region: from biology to control. Parasite. 21.

Hamiroune M, Dahmane M, Cheniguel H, Charef A, Foughalia A (2019) Contribution to the Epidemiological Study on the Main Pathologies of Ruminants Declared in the Central Slaughterhouse of Jijel (Algeria) Bulletin of University of Agricultural Sciences and Veterinary Medicine Cluj-Napoca. Veterinary Medicine 76:183-190

Little SE, Hostetler J, Kocan KM (2007) Movement of Rhipicephalus sanguineus adults between co-housed dogs during active feeding. Veterinary parasitology 150:139-145

Mihalca A et al. (2012) Synopsis of the hard ticks (Acari: Ixodidae) of Romania with update on host associations and geographical distribution Experimental and applied acarology 58:183-206

Nicholson W, Masters E, Wormser G (2009) Preliminary serologic investigation of 'Rickettsia amblyommii'in the aetiology of Southern tick associated rash illness (STARI) Clinical Microbiology and Infection 15:235-236

Schwartz D. 1993. Méthodes statistiques à l'usage des médecins et des biologistes [Statistical methods for physicians and biologists. 3rd ed. Flammarion: Paris, France]. 3eme éd. Paris: Flammarion. French.

Tsunoda, T. (2007). Interspecific and intraspecific associations of two species of hard ticks, Haemaphysalis longicornis and Haemaphysalis megaspinosa, in relation to questing site. Journal of Parasitology, 93(3), 531-541.

Walker AR. 2003. Ticks of domestic animals in Africa: a guide to identification of species. Edinburgh: Bioscience Reports.

Yousfi-Monod R, Aeschlimann A. 1986. Recherches sur les tiques (Acarina, Ixodidae), parasites de bovidés dans l'ouest Algérien. Annales de parasitologie humaine et comparée [Research on ticks (Acarina, Ixodidae), parasites of cattle in western Algeria. Annals of human and comparative parasitology]. 61(3):341-358. French.

\section{Tables}

Table I. Adults tick species association according to cattle age, breed and, sex in Jijel, Algeria. 


\section{Cattle Tick species}

Age Breed Sex R.bursa

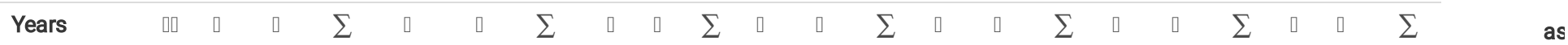

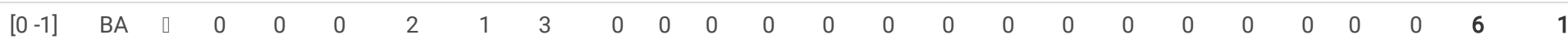

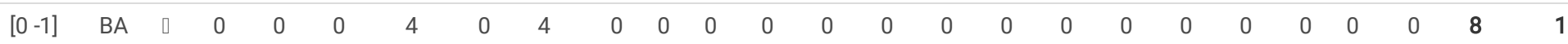

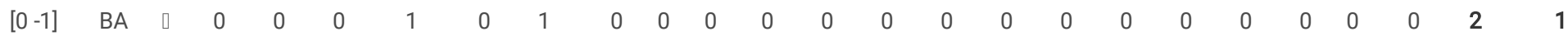

$\left[\begin{array}{lllllllllllllllllllllllllllllll}1-2 & \mathrm{BB} & \mathrm{a} & 1 & 1 & 2 & 40 & 1 & 41 & 0 & 0 & 0 & 0 & 0 & 0 & 0 & 0 & 0 & 0 & 0 & 0 & 0 & 13 & 13 & 112 & 3\end{array}\right.$

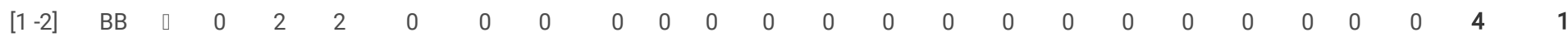

$\left[\begin{array}{lllllllllllllllllllllllllllllllll}1-2] & \mathrm{BB} & \mathrm{a} & 4 & 2 & 6 & 2 & 0 & 2 & 0 & 0 & 0 & 1 & 5 & 6 & 0 & 1 & 1 & 1 & 0 & 1 & 0 & 0 & 0 & 32 & 4\end{array}\right.$

$\begin{array}{lllllllllllllllllllllllllllllll}1-2 & \mathrm{BB} & \mathrm{a} & 3 & 4 & 7 & 1 & 0 & 1 & 0 & 0 & 0 & 0 & 5 & 5 & 0 & 0 & 0 & 4 & 0 & 4 & 0 & 0 & 0 & \mathbf{3 4} & \mathbf{4}\end{array}$

$\left[\begin{array}{llllllllllllllllllllllllllllllll}1-2] & \mathrm{BB} & \mathrm{a} & 0 & 0 & 0 & 0 & 0 & 0 & 0 & 0 & 0 & 0 & 2 & 2 & 0 & 0 & 0 & 0 & 2 & 2 & 0 & 0 & 0 & \mathbf{8} & \mathbf{2}\end{array}\right.$

$\left[\begin{array}{lllllllllllllllllllllllllllllllll}{[2-3]} & \mathrm{BA} & \mathrm{a} & 1 & 0 & 1 & 8 & 0 & 8 & 0 & 0 & 0 & 0 & 0 & 0 & 0 & 0 & 0 & 0 & 0 & 0 & 2 & 0 & 2 & 22 & 3\end{array}\right.$

$\left[\begin{array}{lllllllllllllllllllllllllllllll}{[2-3]} & \text { BA } & \square & 15 & 6 & 21 & 2 & 0 & 2 & 0 & 0 & 0 & 0 & 0 & 0 & 0 & 0 & 0 & 0 & 0 & 0 & 0 & 0 & 0 & 46 & 2\end{array}\right.$

$\left[\begin{array}{lllllllllllllllllllllllllllllllll}2-3 & \text { BA } & 0 & 0 & 0 & 0 & 30 & 0 & 30 & 0 & 0 & 0 & 0 & 0 & 0 & 0 & 0 & 0 & 0 & 0 & 0 & 0 & 0 & 0 & 60 & 1\end{array}\right.$

$\begin{array}{lllllllllllllllllllllllllllllllllll}{[2-3]} & \mathrm{BA} & \mathrm{a} & 0 & 0 & 0 & 9 & 0 & 9 & 0 & 0 & 0 & 0 & 0 & 0 & 0 & 0 & 0 & 0 & 0 & 0 & 0 & 0 & 0 & 18 & 1\end{array}$

$\left[\begin{array}{llllllllllllllllllllllllllllllllll}{[2-3]} & \text { BA } & \square & 4 & 4 & 8 & 1 & 0 & 1 & 0 & 0 & 0 & 0 & 0 & 0 & 0 & 0 & 0 & 0 & 0 & 0 & 0 & 0 & 0 & 18 & 2\end{array}\right.$

$\left[\begin{array}{lllllllllllllllllllllllllllllllll}{[2-3]} & \mathrm{BA} & \mathrm{a} & 0 & 0 & 0 & 2 & 0 & 2 & 0 & 0 & 0 & 0 & 0 & 0 & 0 & 0 & 0 & 1 & 3 & 4 & 0 & 0 & 0 & 12 & 2\end{array}\right.$

$\begin{array}{llllllllllllllllllllllllllllllll}{[2-3]} & \mathrm{BB} & \square & 1 & 2 & 3 & 2 & 0 & 2 & 0 & 0 & 0 & 0 & 4 & 4 & 0 & 0 & 0 & 1 & 0 & 1 & 0 & 1 & 1 & 22 & 5\end{array}$

$\left[\begin{array}{lllllllllllllllllllllllllllllllll}3-4] & \text { BB } & \square & 0 & 0 & 0 & 9 & 2 & 11 & 0 & 0 & 0 & 0 & 0 & 0 & 0 & 0 & 0 & 0 & 0 & 0 & 0 & 0 & 0 & 22 & 1\end{array}\right.$

$\left[\begin{array}{lllllllllllllllllllllllllllllll}{[3-4]} & \mathrm{BB} & \mathrm{a} & 0 & 0 & 0 & 81 & 8 & 89 & 0 & 0 & 0 & 0 & 0 & 0 & 0 & 3 & 3 & 0 & 3 & 3 & 0 & 0 & 0 & 190 & 3\end{array}\right.$

$\left[\begin{array}{llllllllllllllllllllllllllllllll}{[3-4]} & \mathrm{BB} & \mathrm{a} & 3 & 2 & 5 & 3 & 0 & 3 & 0 & 0 & 0 & 0 & 1 & 1 & 2 & 3 & 5 & 0 & 3 & 3 & 0 & 0 & 0 & 34 & 5\end{array}\right.$

$\left[\begin{array}{lllllllllllllllllllllllllllllllll}4-5] & \mathrm{RL} & \mathrm{a} & 0 & 1 & 1 & 50 & 6 & 56 & 0 & 0 & 0 & 0 & 0 & 0 & 0 & 3 & 3 & 0 & 0 & 0 & 0 & 0 & 0 & 120 & 3\end{array}\right.$

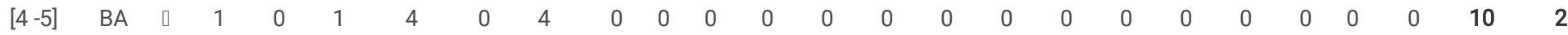

$\left[\begin{array}{llllllllllllllllllllllllllllllll}4-5 & \mathrm{RL} & \mathrm{a} & 3 & 3 & 6 & 0 & 0 & 0 & 0 & 0 & 0 & 0 & 0 & 0 & 0 & 0 & 0 & 0 & 4 & 4 & 0 & 0 & 0 & 20 & 2\end{array}\right.$

$\left[\begin{array}{lllllllllllllllllllllllllllllllll}4-5] & \mathrm{BB} & \mathrm{a} & 0 & 3 & 3 & 0 & 0 & 0 & 3 & 1 & 4 & 0 & 1 & 1 & 0 & 1 & 1 & 0 & 0 & 0 & 0 & 0 & 0 & 18 & 4\end{array}\right.$

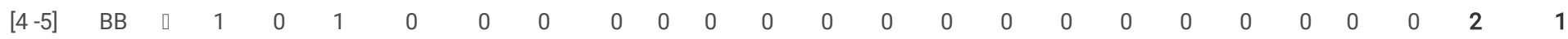

$\left[\begin{array}{lllllllllllllllllllllllllllllll}{[5-6]} & \text { BB } & \square & 1 & 1 & 2 & 109 & 13 & 122 & 0 & 0 & 0 & 0 & 0 & 0 & 0 & 0 & 0 & 0 & 0 & 0 & 0 & 0 & 0 & 248 & 2\end{array}\right.$

$\left[\begin{array}{lllllllllllllllllllllllllllllll}{[5-6]} & \text { BB } & \square & 0 & 0 & 0 & 51 & 7 & 58 & 0 & 0 & 0 & 0 & 0 & 0 & 0 & 0 & 0 & 0 & 0 & 0 & 0 & 0 & 0 & 116 & 1\end{array}\right.$ $\left[\begin{array}{llllllllllllllllllllllllllllll}5-6] & \mathrm{BB} & \square & 2 & 6 & 8 & 4 & 0 & 4 & 0 & 0 & 0 & 0 & 0 & 0 & 0 & 0 & 0 & 2 & 7 & 9 & 0 & 0 & 0 & 42 & 3\end{array}\right.$ $\left[\begin{array}{lllllllllllllllllllllllllllllllll} & -6] & \mathrm{BB} & \mathrm{a} & 0 & 0 & 0 & 46 & 2 & 48 & 0 & 0 & 0 & 0 & 0 & 0 & 0 & 0 & 0 & 0 & 0 & 0 & 0 & 0 & 0 & 96 & 1\end{array}\right.$ $\left[\begin{array}{lllllllllllllllllllllllllllllll}5-6] & \mathrm{BB} & \mathrm{a} & 0 & 2 & 2 & 48 & 10 & 58 & 0 & 0 & 0 & 0 & 0 & 0 & 0 & 0 & 0 & 0 & 0 & 0 & 0 & 0 & 0 & 120 & 2\end{array}\right.$ $\left[\begin{array}{llllllllllllllllllllllllllllllll}5-6] & \text { BA } & \square & 1 & 1 & 2 & 0 & 0 & 0 & 0 & 0 & 0 & 3 & 7 & 10 & 0 & 0 & 0 & 0 & 0 & 0 & 0 & 0 & 0 & 24 & 2\end{array}\right.$ $\left[\begin{array}{llllllllllllllllllllllllllllllll}5-6] & \mathrm{BA} & \mathrm{a} & 0 & 0 & 0 & 4 & 0 & 4 & 0 & 0 & 0 & 0 & 0 & 0 & 0 & 0 & 0 & 0 & 0 & 0 & 0 & 0 & 0 & 8 & 1\end{array}\right.$ $\begin{array}{llllllllllllllllllllllllllllll}{[5-6]} & \text { BA } & \square & 0 & 1 & 1 & 0 & 0 & 0 & 0 & 0 & 0 & 0 & 0 & 0 & 0 & 0 & 0 & 0 & 4 & 4 & 0 & 0 & 0 & 10 & 2\end{array}$ $\left[\begin{array}{llllllllllllllllllllllllllllllll}6-7] & \mathrm{BB} & \mathrm{a} & 0 & 0 & 0 & 8 & 0 & 8 & 0 & 0 & 0 & 0 & 0 & 0 & 0 & 0 & 0 & 0 & 0 & 0 & 0 & 0 & 0 & 16 & 1\end{array}\right.$ $\left[\begin{array}{llllllllllllllllllllllllllllll}6-7] & \mathrm{BB} & \mathrm{a} & 0 & 2 & 2 & 72 & 8 & 80 & 0 & 0 & 0 & 1 & 2 & 3 & 0 & 0 & 0 & 0 & 0 & 0 & 0 & 0 & 0 & 170 & 3\end{array}\right.$ $\left[\begin{array}{llllllllllllllllllllllllllllll}6-7] & \mathrm{BA} & \mathrm{a} & 0 & 0 & 0 & 0 & 0 & 0 & 0 & 0 & 0 & 0 & 7 & 7 & 0 & 0 & 0 & 0 & 0 & 0 & 0 & 0 & 0 & 14 & 1\end{array}\right.$ $\left[\begin{array}{llllllllllllllllllllllllllllllll}6-7] & \mathrm{BA} & \square & 4 & 0 & 4 & 0 & 0 & 0 & 0 & 0 & 0 & 0 & 0 & 0 & 0 & 0 & 0 & 0 & 2 & 2 & 0 & 0 & 0 & 12 & 2\end{array}\right.$ $\left[\begin{array}{llllllllllllllllllllllllllllllll}6-7] & \mathrm{BB} & \mathrm{a} & 3 & 0 & 3 & 0 & 0 & 0 & 0 & 0 & 0 & 0 & 0 & 0 & 0 & 0 & 0 & 0 & 0 & 0 & 0 & 0 & 0 & 6 & 1\end{array}\right.$ $\left[\begin{array}{lllllllllllllllllllllllllllllll}6-7] & \mathrm{BB} & \mathrm{a} & 0 & 3 & 3 & 0 & 0 & 0 & 0 & 0 & 0 & 0 & 0 & 0 & 2 & 1 & 3 & 2 & 0 & 2 & 0 & 0 & 0 & 16 & 3\end{array}\right.$ $\left[\begin{array}{llllllllllllllllllllllllllllll}6-7] & \mathrm{BB} & \square & 0 & 1 & 1 & 0 & 0 & 0 & 0 & 0 & 0 & 1 & 4 & 5 & 0 & 0 & 0 & 2 & 0 & 2 & 0 & 0 & 0 & 16 & 3\end{array}\right.$ 
$\begin{array}{llllllllllllllllllllllllllllllll}{[7-8]} & \mathrm{BB} & \square & 1 & 1 & 2 & 38 & 1 & 39 & 0 & 0 & 0 & 0 & 0 & 0 & 0 & 0 & 0 & 0 & 0 & 0 & 0 & 0 & 0 & 82 & 2\end{array}$

$\begin{array}{lllllllllllllllllllllllllllllllll} & 7-8] & \mathrm{BB} & \mathrm{a} & 0 & 0 & 0 & 66 & 4 & 70 & 0 & 0 & 0 & 0 & 0 & 0 & 0 & 1 & 1 & 0 & 0 & 0 & 0 & 0 & 0 & 142 & 2\end{array}$

\begin{tabular}{llllllllllllllllllllllllllllllll}
\hline $7-8]$ & BB & $\square$ & 1 & 1 & 2 & 11 & 0 & 11 & 0 & 0 & 0 & 0 & 0 & 0 & 0 & 0 & 0 & 0 & 0 & 0 & 0 & 0 & 0 & $\mathbf{2 6}$ & $\mathbf{2}$
\end{tabular}

$\left[\begin{array}{lllllllllllllllllllllllllllllll}7-8 & \mathrm{BB} & \mathrm{a} & 0 & 1 & 1 & 29 & 6 & 35 & 0 & 0 & 0 & 0 & 0 & 0 & 0 & 0 & 0 & 0 & 0 & 0 & 0 & 0 & 0 & 72 & 2\end{array}\right.$

$\left[\begin{array}{lllllllllllllllllllllllllllllll}7-8 & \text { BA } & \square & 9 & 6 & 15 & 5 & 1 & 6 & 0 & 0 & 0 & 0 & 7 & 7 & 0 & 0 & 0 & 0 & 0 & 0 & 0 & 0 & 0 & 56 & 3\end{array}\right.$

$\left[\begin{array}{llllllllllllllllllllllllllllllll}7-8] & \mathrm{BB} & \mathrm{a} & 2 & 3 & 5 & 1 & 0 & 1 & 0 & 0 & 0 & 0 & 1 & 1 & 5 & 3 & 8 & 1 & 0 & 1 & 0 & 3 & 3 & 38 & 6\end{array}\right.$

$\begin{array}{lllllllllllllllllllllllllllllllllll}7 \text {-8] } & \mathrm{RL} & \mathrm{a} & 0 & 0 & 0 & 0 & 0 & 0 & 0 & 0 & 0 & 1 & 3 & 4 & 0 & 0 & 0 & 2 & 0 & 2 & 0 & 0 & 0 & 12 & 2\end{array}$

$\begin{array}{llllllllllllllllllllllllllllllll}7-8] & \mathrm{BB} & \mathrm{a} & 3 & 0 & 3 & 0 & 0 & 0 & 0 & 0 & 0 & 0 & 4 & 4 & 0 & 0 & 0 & 0 & 0 & 0 & 0 & 0 & 0 & 14 & 2\end{array}$

$\left[\begin{array}{lllllllllllllllllllllllllllllll}7-8 & \mathrm{BB} & \mathrm{a} & 0 & 0 & 0 & 0 & 0 & 0 & 0 & 0 & 0 & 2 & 0 & 2 & 0 & 1 & 1 & 1 & 2 & 3 & 0 & 0 & 0 & 12 & 3\end{array}\right.$

$\left[\begin{array}{lllllllllllllllllllllllllllll}7-8] & \mathrm{RL} & \mathrm{a} & 0 & 1 & 1 & 47 & 4 & 51 & 0 & 0 & 0 & 0 & 0 & 0 & 0 & 7 & 7 & 0 & 0 & 0 & 0 & 0 & 0 & 118 & 3\end{array}\right.$

$\left[\begin{array}{llllllllllllllllllllllllllllll}8-9] & \mathrm{RL} & \mathrm{a} & 0 & 0 & 0 & 5 & 1 & 6 & 0 & 0 & 0 & 0 & 0 & 0 & 0 & 1 & 1 & 0 & 0 & 0 & 0 & 0 & 0 & 14 & 2\end{array}\right.$

$\left[\begin{array}{lllllllllllllllllllllllllllllllll}8-9] & \text { BA } & \square & 2 & 0 & 2 & 0 & 0 & 0 & 0 & 0 & 0 & 1 & 1 & 2 & 0 & 0 & 0 & 1 & 1 & 2 & 0 & 0 & 0 & 12 & 3\end{array}\right.$

$\left[\begin{array}{llllllllllllllllllllllllllllllll}10 & \mathrm{BB} & \square & 0 & 1 & 1 & 3 & 0 & 3 & 0 & 0 & 0 & 0 & 1 & 1 & 0 & 4 & 4 & 0 & 1 & 1 & 0 & 0 & 0 & \mathbf{2 0} & \mathbf{5}\end{array}\right.$

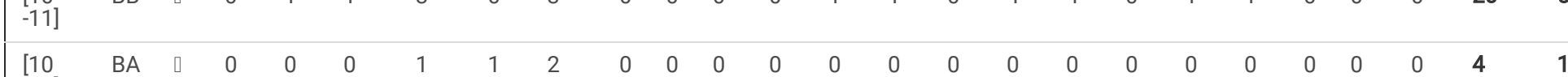

$-11]$

$\begin{array}{lllllllllllllllllllllllllllll}{[10} & \mathrm{BA} & \mathrm{a} & 0 & 0 & 0 & 22 & 9 & 31 & 0 & 0 & 0 & 0 & 2 & 2 & 2 & 1 & 3 & 0 & 0 & 0 & 0 & 0 & 0 & 72 & 3\end{array}$

$\begin{array}{llllllllllllllllllllllll}\text { Total } & 67 & 60 & 127 & 821 & 85 & 906 & 3 & 1 & 4 & 10 & 57 & 67 & 11 & 30 & 41 & 19 & 31 & 50 & 2 & 17 & 19 & 2428\end{array}$

R: Rhipicephalus. H. Hyalomma. BA: Brown Atlas. RL: Red Pied Lowland. BB: Breton Black Pied.

Table 2. Adults tick species association according to cattle age, breed and, sex in Jijel, Algeria.

\begin{tabular}{|c|c|c|c|c|c|c|c|c|c|c|c|c|c|c|c|c|c|c|c|c|c|c|}
\hline \multirow{3}{*}{$\begin{array}{l}\text { Cattle } \\
\text { Age }\end{array}$} & \multicolumn{22}{|c|}{ Ticks species } \\
\hline & \multicolumn{3}{|c|}{ R.bursa } & \multicolumn{3}{|c|}{ R.B.annulatus } & \multicolumn{3}{|c|}{ R. sanguineus } & \multicolumn{3}{|c|}{ H.marginatum } & \multicolumn{3}{|c|}{ H.scupense } & \multicolumn{3}{|c|}{ H.Iusitanicum } & \multicolumn{4}{|c|}{ H.anatolicum } \\
\hline & प & प & $\sum$ & 口 & 口 & $\sum$ & ૫ & ૫ & $\sum$ & ( & प & $\sum$ & प & प & $\sum$ & प & 口 & $\sum$ & 口 & $\square$ & $\Sigma$ & $\sum$ \\
\hline [0 -1] & 0 & 0 & 0 & 7 & 1 & 8 & 0 & 0 & 0 & 0 & 0 & 0 & 0 & 0 & 0 & 0 & 0 & 0 & 0 & 0 & 0 & 16 \\
\hline [1 -2] & 8 & 9 & 17 & 43 & 1 & 44 & 0 & 0 & 0 & 1 & 12 & 13 & 0 & 1 & 1 & 5 & 2 & 7 & 0 & 13 & 13 & 190 \\
\hline [2 -3] & 21 & 12 & 33 & 54 & 0 & 54 & 0 & 0 & 0 & 0 & 4 & 4 & 0 & 0 & 0 & 2 & 3 & 5 & 2 & 1 & 3 & 198 \\
\hline [3 -4] & 3 & 2 & 5 & 93 & 10 & 103 & 0 & 0 & 0 & 0 & 1 & 1 & 2 & 6 & 8 & 0 & 6 & 6 & 0 & 0 & 0 & 246 \\
\hline [4 -5] & 5 & 7 & 12 & 54 & 6 & 60 & 3 & 1 & 4 & 0 & 1 & 1 & 0 & 4 & 4 & 0 & 4 & 4 & 0 & 0 & 0 & 170 \\
\hline [5 -6] & 4 & 11 & 15 & 262 & 32 & 294 & 0 & 0 & 0 & 3 & 7 & 10 & 0 & 0 & 0 & 3 & 10 & 13 & 0 & 0 & 0 & 664 \\
\hline [6 -7] & 7 & 6 & 13 & 80 & 8 & 88 & 0 & 0 & 0 & 2 & 13 & 15 & 2 & 1 & 3 & 4 & 2 & 6 & 0 & 0 & 0 & 250 \\
\hline [7 -8] & 17 & 12 & 29 & 197 & 16 & 213 & 0 & 0 & 0 & 3 & 15 & 18 & 5 & 12 & 17 & 4 & 2 & 6 & 0 & 3 & 3 & 572 \\
\hline [8 -9] & 2 & 0 & 2 & 5 & 1 & 6 & 0 & 0 & 0 & 1 & 1 & 2 & 0 & 1 & 1 & 1 & 1 & 2 & 0 & 0 & 0 & 26 \\
\hline [10 -11] & 0 & 1 & 1 & 26 & 10 & 36 & 0 & 0 & 0 & 0 & 3 & 3 & 2 & 5 & 7 & 0 & 1 & 1 & 0 & 0 & 0 & 96 \\
\hline \multicolumn{23}{|l|}{ Breed } \\
\hline BA & 37 & 18 & 55 & 95 & 12 & 107 & 0 & 0 & 0 & 4 & 24 & 28 & 2 & 1 & 3 & 2 & 10 & 12 & 2 & 0 & 2 & 414 \\
\hline BB & 27 & 37 & 64 & 624 & 62 & 686 & 3 & 1 & 4 & 5 & 30 & 35 & 9 & 18 & 27 & 15 & 17 & 32 & 0 & 17 & 17 & 1730 \\
\hline $\mathrm{RL}$ & 3 & 5 & 8 & 102 & 11 & 113 & 0 & 0 & 0 & 1 & 3 & 4 & 0 & 11 & 11 & 2 & 4 & 6 & 0 & 0 & 0 & 284 \\
\hline \multicolumn{23}{|l|}{ Sex } \\
\hline Males & 16 & 9 & 25 & 54 & 0 & 54 & 3 & 1 & 4 & 0 & 1 & 1 & 0 & 1 & 1 & 0 & 0 & 0 & 2 & 0 & 2 & 174 \\
\hline Females & 51 & 51 & 102 & 767 & 85 & 852 & 0 & 0 & 0 & 10 & 56 & 66 & 11 & 29 & 40 & 19 & 31 & 50 & 0 & 17 & 17 & 2254 \\
\hline
\end{tabular}


B:Rhipicephalus (Boophilus) annulatus, b; Rhipicephalus bursa, s: Rhipicephalus sanguineus,m: Hyalomma marginatum, l; Hyalomma lusitanicum, sc; Hyalomma scupense, a:Hyalomma anatolicum. BA: Brown Atlas. RL: Red Pied Lowland . BB: Breton Black Pied.

Table 3. Association degree and infestation rate of tick species on cattle during summer 2019 in Jijel region, Algeria

\begin{tabular}{|lllll|}
\hline Association degree & Number of cattle infested & Prevalence $\%$ & Number of ticks & Intensity (ticks/cattle) \\
\hline 1 & 15 & 28,30 & 191 & 12 \\
\hline 2 & 18 & 33,96 & 445 & 26 \\
\hline 4 & 13 & 24,53 & 479 & 36 \\
\hline 5 & 3 & 5,66 & 42 & 14 \\
\hline 6 & 3 & 5,66 & 38 & 12 \\
\hline 7 & 1 & 1,89 & 19 & 19 \\
\hline Total & 0 & 0,00 & 0 & 0 \\
\hline
\end{tabular}

\section{Figures}

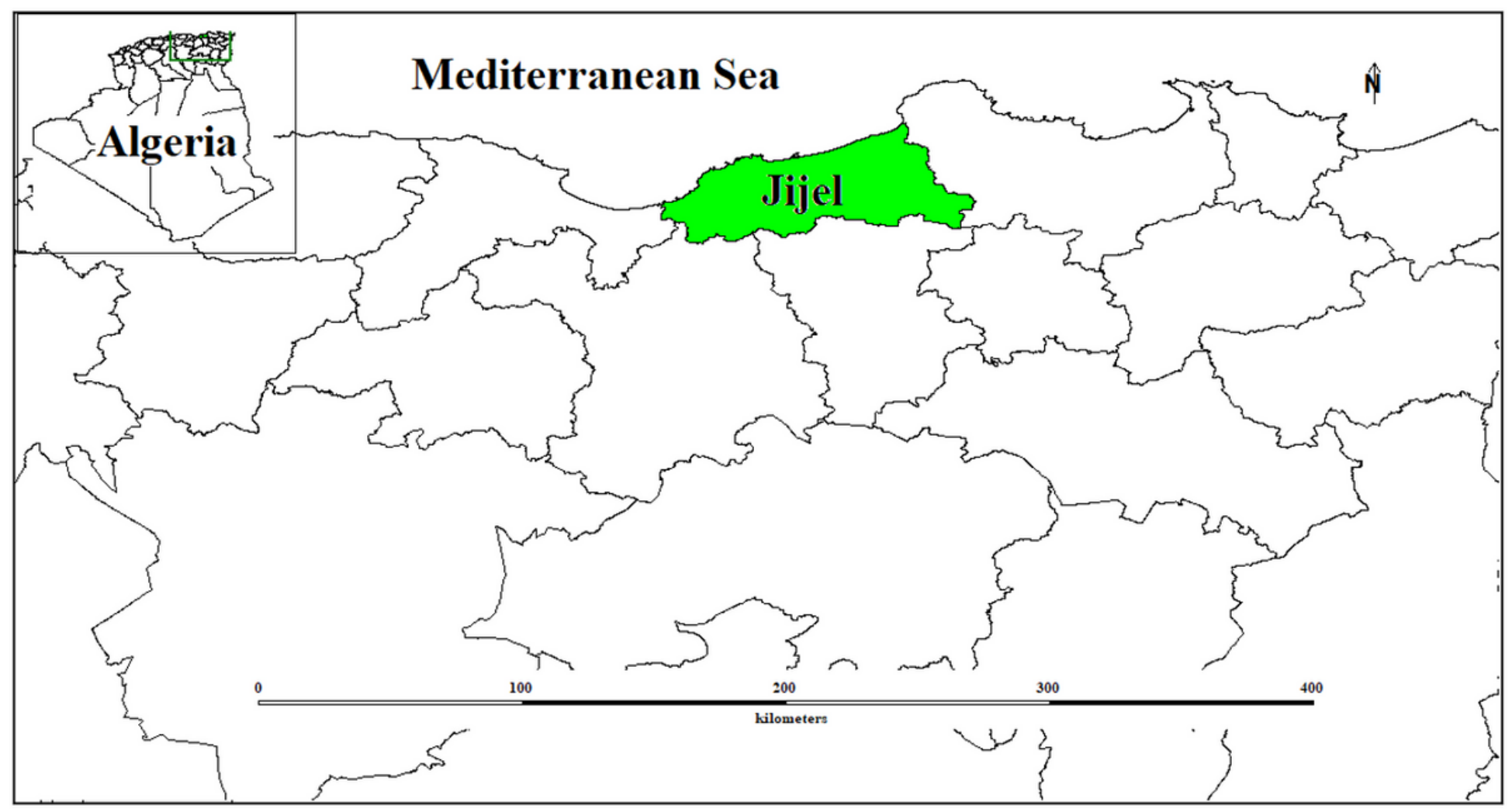

\section{Figure 1}

The geographical location of Jijel province, northeast Algeria(Source: https://www.diva-gis.org/climate). 


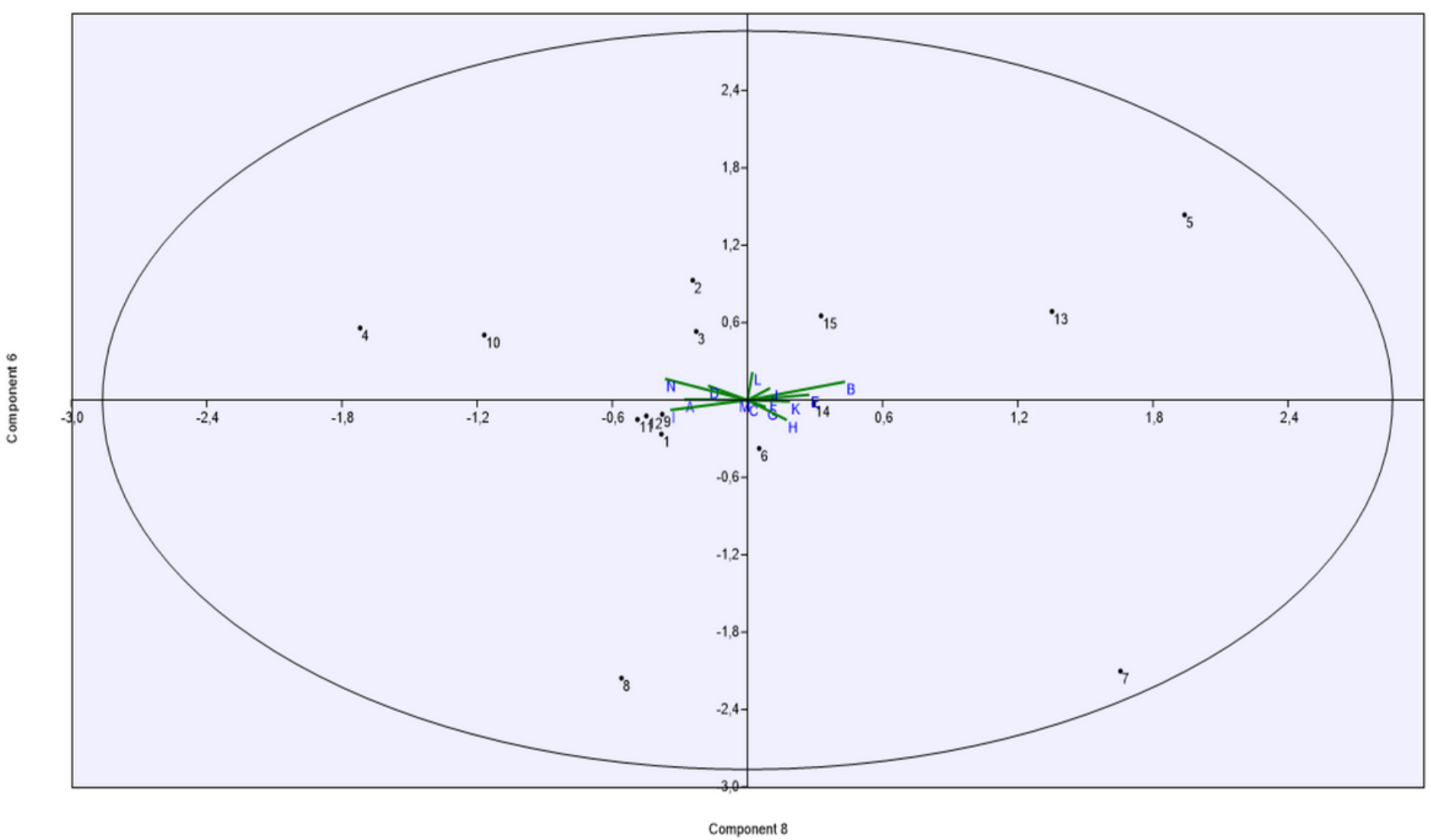

Figure 2

Correlation bi-plot for Principal component analysis of females and males hard tick species on cattle according to cattle age, breed, and sex during summer 2019 in Jijel province, Algeria. 